\title{
Contribuições da formação continuada Na ótica do professor de Ciências Naturais
}

RESUMO: O presente estudo objetivou desvelar as contribuições da formação continuada na visão do professor de Ciências Naturais. Trata-se de uma pesquisa qualitativa descritiva, realizada em cinco escolas vinculadas à Secretaria Municipal de Educação de Teresina-PI, junto a dez professores de Ciências dos anos finais do ensino fundamental. O texto direciona para uma análise do processo de formação continuada, de modo a descortinar as contribuições das atividades formativas oferecidas pela Secretaria de Educação à luz do olhar dos docentes.

Palavras-chave: Formação Continuada. Prática docente. Ensino de Ciências.

\section{Contributions to continuing education \\ From the perspective of a teacher of the Natural Sciences}

\begin{abstract}
The present study aims to reveal contributions to continuing education from the point of view of the Natural Sciences teacher. This is a descriptive qualitative research and was carried out in five schools linked to the Teresina-PI Municipal Education Department, together with ten science teachers working with students in the final years of elementary education. The text moves to an analysis of the process of continuous formation, in order to uncover the
\end{abstract}

* Mestre em Educação pelo Programa de Pós-Graduação em Educação da Universidade Federal do Piauí (UFPI) e licenciado em Ciências Biológicas pela e Pedagogia. Atualmente é docente permanente no Instituto Federal do Maranhão (IFMA). É membro do Grupo de Estudos e Pesquisas sobre o Ensino e Formação de Professores de Ciências (GRUPEC) e do Núcleo de Formação de Professores. Teresina/PI - Brasil. E-mail: <caio.veloso@ifma.edu.br>.

* Doutor em Educação pela Universidade Federal de Santa Catarina é especialista em ensino de física. Atualmente é professor da Universidade Federal do Piauí, onde atua no Programa de Pós-Graduação em Educação. Teresina/PI - Brasil. E-mail: <jacms@uol.com.br>. 
contributions of the formative activities offered by the Department of Education in the light of the teachers' perspective.

Keywords: Continuing education. Teaching practice. Science teaching.

\section{Contribuciones de la formación continua}

Desde la perspectiva del profesor de Ciencias Naturales

RESUMEN: El objetivo de este estudio es mostrar las contribuciones de la formación continua desde la perspectiva del profesor de Ciencias Naturales. Se trata de una encuesta cualitativa descriptiva, realizada en cinco escuelas vinculadas a la Secretaría Municipal de Educación de Teresina, estado de Piauí, con la participación de diez profesores de Ciencias de las etapas finales de la enseñanza fundamental. El texto conduce a un análisis del proceso de formación continua con el fin de revelar las contribuciones de las actividades formativas ofrecidas por la Secretaría de Educación según la perspectiva de los docentes.

Palabras clave: Formación continua. Práctica docente. Enseñanza de Ciencias.

\section{Contributions de la formation continue}

Selon les professeurs de Sciences Naturelles

RÉSUMÉ: Cette présente étude visait à expliciter les contributions de la formation continue dans la vision du professeur de Sciences Naturelles. Il s'agit d'une recherche qualitative descriptive, réalisée dans cinq écoles liées au Secrétariat Municipal d' éducation de Teresina-, état du Piaui, auprés de dix professeurs de sciences des dernières années de l'enseignement primaire. Le texte s'oriente vers une analyse $\mathrm{du}$ processus de formation continue, de manière à montrer les contributions des activités de formation offertes par le Secrétariat d'éducation à l'aune du regard des enseignants.

Mots-clés: Formation continue. Pratique enseignante. Enseignement des sciences. 


\section{Introdução}

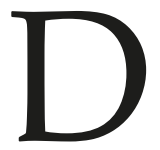

enominamos de formação continuada de professores os diversos processos que possibilitam o aprofundamento e a construção de novos conhecimentos pelo docente, por meio de palestras, seminários, cursos e oficinas sistematizadas, de modo a intencionar a melhoria das práticas pedagógicas e a formação de indivíduos críticos e reflexivos. Essa formação articula-se com o desenvolvimento institucional e pessoal do professor, como preconiza Nóvoa (1995).

Para Menezes (1996), é um processo a longo prazo que não é finalizado com a obtenção do título de licenciado, mesmo que a formação seja da mais alta qualidade. Isso ocorre porque a formação de professores é um processo complexo para o qual são necessários muitos conhecimentos e habilidades, que nem sempre são adquiridos no curto espaço de tempo da graduação.

Ademais, durante o trabalho em sala de aula surgem, constantemente, novas situações que o professor precisa enfrentar. Assim, é importante que ele disponha de possibilidades de formação continuada, diversificadas e de qualidade, de modo que a formação investigue os problemas do ensino-aprendizagem no âmbito das Ciências Naturais levando, consequentemente, ao desenvolvimento das práticas docentes.

Analisamos a formação continuada diretamente ligada ao papel do professor, às possibilidades de transformação de suas práticas docentes e às possíveis mudanças no contexto escolar. Imbernón (2010) defende que a formação continuada como fomento de desenvolvimento pessoal, profissional e institucional dos professores eleva o seu trabalho para a transformação de uma prática. Essa prática está para além das atualizações científicas, didáticas ou pedagógicas do trabalho docente. A formação continuada supõe uma prática cujo alicerce é balizado na teoria e na reflexão para a mudança e visa a transformação do contexto escolar.

Assim, esta pesquisa emergiu do contexto que vivenciamos enquanto professor de Ciências Naturais e Biologia no município de Teresina-PI, onde visualizamos a necessidade de uma formação continuada sistematizada, que ocorra em um contínuo, seja interativa e combine uma variedade de aprendizagens que propiciem o desenvolvimento profissional ${ }^{1}$.

Diante da pertinência da problemática exposta, somada à necessidade de maior difusão do conhecimento de cunho científico, esta pesquisa objetivou desvelar as contribuições da formação continuada na visão do professor de Ciências Naturais.

Compreendemos que essa investigação é relevante por evidenciar a formação continuada de professores no âmbito do ensino de Ciências Naturais, além de revelar os anseios dos interlocutores da pesquisa quanto à dinâmica de formação. Os resultados obtidos no estudo fortalecem a discussão sobre a temática em voga e possibilitam o aperfeiçoamento das atividades de formação continuada ofertadas pelo Centro de Formação 
Professor Odilon Nunes, instituição responsável pela formação continuada dos professores da Secretaria Municipal de Educação de Teresina-PI.

Com o intuito de atender ao objetivo proposto e sistematizar o estudo, estruturamos este texto em cinco seções. Na introdução, contextualizamos a temática e apresentamos o objetivo da investigação. Na segunda seção, trouxemos alguns pressupostos gerais acerca da formação continuada de professores. Em seguida, explicitamos a metodologia da pesquisa empírica, caracterizando-a, revelando o lócus do estudo, interlocutores, técnica de coleta de dados, além dos procedimentos de coleta e análise das informações. Posteriormente, na seção quatro, discutimos as contribuições da formação continuada do professor de Ciências, à luz das falas dos interlocutores e dos teóricos que trabalham o objeto. Por fim, apresentamos algumas considerações finais, com base nas discussões realizadas.

\section{Pressupostos gerais acerca da formação continuada}

Na formação docente, ainda persiste a dissociação entre a teoria trabalhada e a prática cotidiana. No contexto da formação continuada é muito comum verificar atividades que não contemplam a realidade específica dos docentes conduzidas por um formador que não concebe o professor como sujeito ativo da sua formação.

A respeito dessa problemática, Libâneo (2002, p. 73) afirma que o aprender a ser professor, na formação continuada, "[...] se pauta por objetivos de aprendizagem que incluem a capacidade e competências esperadas no exercício profissional do professor". Sugere ainda que o melhor programa de formação de professores "[...] seria aquele que contemplasse melhor, no currículo e na metodologia, os princípios e processos de aprendizagens válidos para os alunos das escolas comuns". Isso requer um exercício incessante de reflexão por parte do docente. Para Brito (2005, p. 48),

A reflexão possibilita ao(à) professor(a), compreensão e análise racional de sua ação docente na perspectiva de melhor sistematizá-la e operacionalizá-la. Permite, ainda, que o(a) docente desenvolva, a partir de uma postura crítica e da percepção da natureza da ação pedagógica, saberes relativos ao seu ofício, considerando que sua prática, por seu caráter situado histórico e social, extrapola a mera aplicação de técnicas e de transmissão de conteúdos.

Assim, para que a prática se torne reflexiva, é fundamental que os professores definam os seus objetivos pedagógicos, afastando a ideia de serem técnicos que repassam o saber, para agir como mediadores visando à apropriação do conhecimento pelo aluno. Para isso, a formação continuada de professores procura investir e valorizar o desenvolvimento dos saberes docentes, considerando esses profissionais como 
intelectuais capazes de incrementar novas práticas, que propiciem a evolução do ensino de modo a favorecer o acesso do educando ao saber escolar e científico.

Para isso, faz-se necessário investimentos em atividades de formação continuada de professores. Tardif (2005) afirma que é preciso promover espaços para que o professor possa refletir sobre a sua prática em um movimento de ação-reflexão-ação, como também buscar maior integração entre a formação que se realiza na universidade e a prática das escolas.

Mendes Sobrinho (2006) corrobora com a ideia supracitada ao defender a importância e a necessidade da formação continuada, de forma a considerar a realidade concreta do professor e os problemas que ele se depara em sua prática. Sobre o tema, afirma que:

\begin{abstract}
A formação do futuro professor - através das licenciaturas específicas - não tem correspondido plenamente a uma formação geral satisfatória, nem a uma formação pedagógica consciente. Há um descompasso entre a teorização na formação do professor e a sua atuação pedagógica. Esse quadro aponta para a necessidade de implementação de uma prática educacional que trate a formação e a atuação de forma mais rigorosa, competente e interdependente, possibilitando a interpretação e reflexão, próprias da atividade do professor. (MENDES SOBRINHO, 2006, p. 89).
\end{abstract}

A formação continuada é indispensável ao professor, já que os cursos de graduação não têm atendido plenamente à formação de um docente crítico, reflexivo e antenado com o mundo globalizado que a escola necessita.

Urzetta e Cunha (2013) defendem que a formação docente é um processo não finalizado com o término da formação inicial, ao contrário, tem-se como fundamental a formação continuada, em que as reflexões sobre práticas profissionais se tornem a base desse processo, no qual a formação é o resultado da vivência teórica e prática, permitindo que o professor possa tecer alternativas para o desenvolvimento profissional.

Ademais, a formação continuada estende-se ao terreno das capacidades, habilidades e atitudes, questionando permanentemente os valores e as concepções de cada professor e de toda a equipe. Propõe, ainda, um processo que confira ao docente conhecimentos, habilidades e atitudes para formar profissionais reflexivos e investigadores. Nesse âmbito, Soares e Mendes Sobrinho (2013) afirmam que a reflexão pode abrir novas possibilidades para a ação, propiciando o desenvolvimento da prática docente e potencializando a transformação que se deseja.

Não se pode mais considerar as atividades de formação continuada como processos de acúmulo ou aprendizado de novas técnicas, deixando de lado a reflexão crítica sobre as práticas docentes e sobre a atuação do professor em sala de aula. Moreira (2002) defende que, ao considerar as atividades de formação continuada como receituários, ela passa a ser tomada isoladamente, sem levar em consideração outras dimensões do 
exercício profissional, ficando direcionada, basicamente, a corrigir e destacar falhas da prática docente.

A formação continuada tem, entre outros objetivos, " [...] propor novas metodologias e colocar os profissionais informados quanto às discussões teóricas atuais, com a intenção de contribuir para as mudanças que se fazem necessárias à melhoria da ação pedagógica na escola". (MOREIRA, 2002, p. 55).

Além disso, ela busca aumentar a autoestima do professor; ajudá-lo a (re)descobrir sua competência profissional; permitir o acesso ao conhecimento acadêmico produzido na universidade; além de proporcionar a socialização de vivências oriundas do trabalho diário, de modo a considerar o professor um produtor e multiplicador de diferentes saberes.

A formação continuada, portanto, está para além de uma mera atualização científica. Ela busca, principalmente, possibilitar ao professor lidar melhor com as diversas situações que ocorrem no ambiente escolar, permitindo-lhe tomar decisões acertadas, agir de maneira crítica e reflexiva. Além disso, objetiva também permitir o desenvolvimento das práticas docentes, favorecendo a melhoria da ação do professor, convergindo, assim, para o que Nóvoa (1995) denomina de desenvolvimento pessoal, profissional e institucional.

Após discutir as características básicas da formação continuada de professores, apresentaremos a metodologia empregada no desenvolvimento da investigação.

\section{Delineamento metodológico da pesquisa}

Para a realização deste estudo, optamos por desenvolver uma pesquisa qualitativa descritiva. Segundo Triviños (1992, p. 110), a pesquisa qualitativa descritiva pretende "[...] descrever com exatidão os fatos e fenômenos de uma determinada realidade". Tem, pois, como interesse principal fazer com que o pesquisador conheça a realidade pesquisada para, dessa forma, obter conclusões significativas.

Assim, entendemos que a pesquisa qualitativa descritiva seria eficaz para desvelar as contribuições da formação continuada na visão do professor de Ciências Naturais dos anos finais do ensino fundamental.

Em relação ao lócus, a pesquisa foi desenvolvida em cinco escolas públicas vinculadas à Secretaria Municipal de Educação, localizadas na zona urbana do município de Teresina-PI. Os dados foram coletados no período de fevereiro a junho de 2015.

Participaram como interlocutores desta investigação, dez professores que atenderam aos seguintes critérios: serem docentes efetivos da rede municipal de ensino de Teresina-PI, ministrarem a disciplina Ciências Naturais em turmas dos anos finais do ensino fundamental (6ํㅜa $9^{\circ}$ ano), e serem graduados em Ciências Biológicas, Física ou 
Química. Cada professor confirmou a participação por meio da assinatura de um Termo de Consentimento Livre e Esclarecido (TCLE).

Para assegurar o anonimato dos interlocutores, utilizamos uma codificação própria para identificar cada um deles. Para isso, escolhemos nomes de pesquisadores que contribuíram de forma efetiva para o desenvolvimento da produção científica no Brasil.

Eles foram, então, denominados: Bertha Lutz (bióloga reconhecida internacionalmente pelas valiosas contribuições na pesquisa zoológica, especificamente sobre anfíbios brasileiros); Carlos Chagas (médico sanitarista que descobriu a doença que leva o seu nome e mapeou a carta epidemiológica da Floresta Amazônica); Duília de Mello (astrônoma brasileira que cuida de projetos da Nasa e descobriu a estrela supernova 1997D); Elisa Frota (física que introduziu a técnica de emulsões nucleares no Brasil); Graziela Maciel (botânica considerada a maior catalogadora de plantas do Brasil); Maria José (parasitologista que muito contribuiu para a saúde pública do País através da erradicação de epidemias); Marta Vannucci (bióloga, uma das mais renomadas pesquisadoras de manguezais do mundo); Neusa Amato (física que trabalhou com a detecção de raios cósmicos de alta energia); Maurício Rocha (químico que descobriu a bradicinina, usada no tratamento e controle da hipertensão); e Oswaldo Cruz (cientista que erradicou doenças endêmicas como a peste bubônica e a varíola).

Como técnica de coleta de dados, utilizamos a entrevista semiestruturada, por permitir que os investigados tenham certa liberdade para relatar as experiências e o pesquisador, a partir das respostas obtidas, poder alterar a sequência dos questionamentos ou até aprofundar as informações por meio de novas perguntas, desde que dentro do foco pretendido.

As entrevistas semiestruturadas foram realizadas individualmente, em local e horário definidos pelos interlocutores e permitiram que eles falassem sobre as contribuições da formação continuada desenvolvida pelo Centro de Formação Professor Odilon Nunes, instituição inaugurada em maio de 2007, hoje responsável pela oferta de atividades formativas aos professores vinculados à Secretaria Municipal de Educação de Teresina-PI.

No que se refere à formação em análise, convém esclarecer que as atividades formativas eram elaboradas pelo Instituto Qualidade de Ensino (IQE), com sede na cidade de São Paulo, por meio do programa Qualiescola. Esse programa propõe a melhoria da qualidade do ensino e da aprendizagem dos alunos de escolas públicas do ensino fundamental, por meio de um conjunto de ações articuladas de intervenção na prática escolar.

Dentre as ações principais desse programa, destaca-se a formação continuada de professores, por meio de oficinas presenciais semanais e estudo de materiais de apoio durante os dois anos e meio de duração. Esse programa necessita de formadores, profissionais indicados pela Secretaria de Educação, capacitados pelo IQE para atuar junto aos professores cursistas. 
Os dados foram analisados mediante as seguintes fases: pré-análise, descrição analítica e, por fim, a interpretação inferencial, que consistiu em refletir, de modo a se estabelecer relações entre a realidade pesquisada, fazendo as inferências possíveis, conforme Bardin (2011).

O estudo seguiu as normas e procedimentos éticos da Resolução 466/2012 e foi aprovado pelo Comitê de Ética em Pesquisa local (CEP) (CAAE 38714514.3.0000.5214), após autorização prévia da Secretaria Municipal de Educação de Teresina-PI e da direção das instituições envolvidas.

\section{A formação continuada na visão dos professores}

Na contemporaneidade, a formação continuada tem ocupado posição de destaque em discussões no âmbito da educação e da formação de professores. Compreendemos que ela é essencial à formação de um profissional investigador da sua prática, de forma a orientar o desenvolvimento de estratégias que permitam a superação dos problemas cotidianos no ambiente escolar.

Essa formação, segundo Nóvoa (1995), propicia ao professor o desenvolvimento pessoal, representado pelo crescimento individual oriundo da formação; profissional, demonstrado pela aquisição e aperfeiçoamento de competências para ensinar; e organizacional, permitindo a socialização profissional em uma escola ou instituição.

$\mathrm{O}$ aspecto considerado nesta pesquisa, ao analisar a formação continuada de professores, refere-se à visão dos interlocutores acerca das contribuições da formação, principalmente no contexto das Ciências Naturais, foco desse estudo.

A partir da fala dos docentes, emergiram opiniões que instigam a discussão a respeito da formação continuada, no que concerne às suas contribuições à luz do pensamento do professor. Assim, dispomos de alguns excertos, nos quais, questionados sobre a participação dos professores em atividades de formação continuada, os interlocutores esboçam sua concepção :

[...] Eu sou professor de Ciências... a ciência nunca para, ela está sempre evoluindo e a gente tem que ficar sempre se reciclando, pois as novidades estão aí, sempre chegando. Então é necessário estar participando de formações vinculadas ao nosso trabalho. (CARLOS CHAGAS).

Muito contribui, porque eu mesma, como professora, não tenho muito tempo de estar na internet e pesquisando livros para estimular as crianças. Porque a ciência, como você sabe, não está parada, ela muda, está sempre sofrendo mutação, está sempre acontecendo alguma coisa nova. E como a gente não tem muito tempo para isso, por trabalhar os três turnos, com essas formações temos a oportunidade de alguém que já tem esse conhecimento maior, poder discutir isso conosco; vamos adquirindo mais conhecimento. (MARTA VANNUCCI). 
A formação contribuiu para que possamos estar por dentro do que a ciência tem de novo e também para estarmos em contato com as novas formas de ensinar, novos recursos didáticos e ainda para compartilharmos as boas experiências com os colegas de trabalho. Com certeza a formação continuada é enriquecedora. (MAURÍCIO ROCHA).

Observa-se nas falas que os interlocutores da pesquisa consideram importante a formação continuada de professores. Dentre as justificativas, destaca-se a de que a formação continuada propicia atualização científica.

A justificativa de que a ciência não é estática e que, por esse motivo, é necessário estar constantemente atualizado ficou clara no depoimento do professor Carlos Chagas e da professora Marta Vannucci, o que denota a ideia de que a formação continuada de professores visa, basicamente, à atualização de conteúdos. Outros interlocutores também corroboram com essa opinião, como a professora Graziela Maciel, ao afirmar que "[...] todo profissional precisa estar sempre procurando novas informações para melhorar o seu trabalho" e o professor Oswaldo Cruz que considera importantes as atividades de formação continuada porque nelas "[...] novas informações são lançadas, propiciando enriquecer o conhecimento".

Também é recorrente na fala dos interlocutores a visão de que a formação continuada de professores propicia o conhecimento sobre novas metodologias de ensino, favorecendo o desenvolvimento das aulas:

Contribui, porque a formação continuada vem nos mostrar o que há de novo, uma nova prática, uma nova abordagem, uma nova técnica. Então, acho que o professor participar de uma formação continuada é válido, porque ele, de certa forma, estará se reavaliando também, transformando a sua prática. (ELISA FROTA).

A gente tem que estar sempre se preparando para essa nova geração que está vindo. É preciso acompanhar a evolução das tecnologias do conhecimento, temos que estar sempre nos atualizando no sentido de procurar as melhores formas de ensinar. (BERTHA LUTZ).

Qualquer profissão tem que ter formação continuada, principalmente a docente. Não só pela questão das novas técnicas, porque eu, por exemplo, busco isso mesmo não estando na escola. Em qualquer lugar estou buscando informação. Não é muito pela questão da novidade, mas funciona como terapia para quem está conversando, para quem está vendo o que o outro está enfrentando, se está enfrentando um problema igual ao meu [...]. Cada dia, cada hora é uma nova hora, é uma nova vivência... a formação é uma terapia, ela te dá uma injeção de ânimo para a sala de aula. Traz uma energia nova que contagia a gente e eu gosto dessa dinâmica. (MARIA JOSÉ).

Os fragmentos explicitam o entender das interlocutoras acerca da relação entre a formação continuada e o desenvolvimento de metodologias e recursos didáticos.

Mesmo propiciando a construção de novos conhecimentos científicos e o desenvolvimento das práticas docentes, como foi defendido por grande parte dos pesquisados, 
a formação continuada de professores objetiva contemplar a reflexão sobre o saber e o saber-fazer do professor, possibilitando transformações na instituição escolar. (MENDES SOBRINHO, 2006).

Segundo Moreira (2002), a formação continuada propõe novas metodologias e coloca os professores em contato com discussões teóricas atuais, visando melhorar a ação pedagógica na escola, como foi defendido por grande parte dos interlocutores.

Ela faz-se necessária pelas contribuiç̧ões ao desenvolvimento de novas metodologias, pelas discussões teóricas quanto aos conteúdos científicos e pela socialização de experiências entre docentes. Entretanto, Tardif (2005) defende que ela promove espaços para que o professor reflita sobre sua prática docente em um movimento constante de ação-reflexão-ação.

Imbernón (2006) complementa que a formação continuada se apoia em uma reflexão do professor sobre sua prática docente, de modo a permitir-lhe analisar suas teorias, esquemas e atitudes, realizando um processo constante de autoavaliação. A professora Elisa Frota corrobora com essa ideia, ao afirmar que a participação em atividades de formação continuada é válida por propiciar reavaliação e transformação da prática docente.

Também merece destaque nesta análise, a fala da professora Maria José, quando diz que "[...] a formação é uma terapia, ela te dá uma injeção de ânimo para a sala de aula. Traz uma energia nova que contagia a gente e eu gosto dessa dinâmica". Essa fala vai ao encontro do pensamento de Selles (2002) de que a formação continuada visa o aumento da autoestima do professor.

As atividades de formação, quando bem planejadas, tendem a levar os cursistas à reflexão sobre sua prática docente e o desejo de melhorar continuamente pode ser aflorado. Permitem ao professor ressignificar sua prática em sala de aula com vistas à apropriação de conhecimento pelo aluno, põem em prática os novos aprendizados e procuram sanar as inquietações típicas de seu trabalho. Nessa perspectiva, Soares e Mendes Sobrinho (2013) defendem que a reflexão pode abrir novas possibilidades para a ação, propiciando o melhoramento da prática docente.

Chama bastante atenção nos relatos a importância do trabalho colaborativo por parcela significativa dos interlocutores. Mesmo sem usar o termo 'trabalho colaborativo', convergem para a defesa de uma formação pautada no trabalho em equipe, apresentando seus benefícios:

De certa forma acrescenta alguma coisa. No meu caso, se houvesse uma formação com práticas seria muito bom. Agora, eu, pelo menos, nunca tive essa sorte de ter uma formação que me ensinasse práticas, experiências para aplicar nas escolas. As formações que eu tenho tido são mais de discussão. O que é bom é que a gente encontra as pessoas e partilha as dificuldades. Às vezes, a gente encontra um professor que faz alguma coisa diferente e acaba aprendendo também. (DUÍLIA DE MELLO). 
Lá na formação que eu tive da prefeitura aprendi muito porque aprendemos com os colegas. [...] tínhamos a oportunidade de compartilhar experiências, podíamos ver a realidade de várias escolas. Com certeza eu aprendi muito. Por isso que as formações continuadas são importantes, muita coisa trabalhada dava para aplicar em sala de aula, outras não, mas, enfim, temos contato com outras realidades, compartilhamos com os colegas. (NEUSA AMATO).

A professora Duília de Mello defende que, nas atividades de formação continuada, tem a oportunidade de encontrar outros professores de Ciências Naturais, o que permite a discussão sobre as dificuldades com as quais se deparam no cotidiano escolar. Além disso, afirma que, com as discussões, conhecem mais sobre os procedimentos metodológicos adotados pelos colegas de profissão, propiciando o conhecimento acerca de novos métodos e técnicas de ensino.

O relato em tela vai ao encontro do pensamento da professora Neusa Amato, quando diz que nas atividades de formação continuada os docentes têm a oportunidade de compartilhar experiências por meio do contato com a realidade de outras escolas. A professora Maria José corrobora com Neusa Amato quando afirma que a formação continuada é muito importante "[...] para quem está vendo o que o outro está enfrentando, se está enfrentando um problema igual ao meu".

Ao afirmar que "[...] as interações com os colegas são de grande importância para enriquecer o conhecimento", o professor Oswaldo Cruz sintetiza as ideias expostas pelos demais interlocutores, confirmando o entendimento de Procópio et al (2011) de que a rede de colaboração é fundamental para a reflexão, pois torna os professores metacognitivos sobre suas ações, permite explorar a sua ação profissional, estudar os dilemas do professor a partir da sua perspectiva e, principalmente, permite que os professores possam trocar informações e experiências.

Acreditamos que trabalhar a formação de professores de modo colaborativo é promissor por favorecer a construção da autonomia tão almejada para esses profissionais. As discussões em grupo auxiliam a reflexão crítica, enriquecem as atividades formativas, levam à análise e posterior aprimoramento de procedimentos metodológicos, de modo a permitir a constante melhoria do ensino de Ciências Naturais.

\section{Considerações finais}

A formação continuada é um processo promissor (ainda hoje voltado em demasia ao acúmulo e à reprodução de conhecimentos), mas capaz de gerar mudanças no ensino de Ciências Naturais de modo a permitir a aquisição de competências e saberes que possibilitem ao aluno compreender as informações, bem como refletir criticamente sobre o mundo e nele agir com autonomia. 
Com base nas falas dos professores de Ciências Naturais, interlocutores da pesquisa, desvelamos as contribuições da formação continuada à luz do pensamento docente. Observamos que, em consonância com os autores que compõem nosso referencial teórico, os professores, de modo geral, consideram-na imprescindível à atualização científica e capaz de propiciar conhecimentos acerca de novos procedimentos metodológicos de ensino.

Além disso, favorece a melhoria da qualidade das aulas; propicia o aumento da autoestima do professor; promove espaços de reflexão, gerando o movimento ação-reflexão-ação; e permite ao docente analisar suas teorias, atitudes, em um processo constante de autoavaliação.

Fica explícito ainda, nos relatos, que tudo isso torna-se mais efetivo quando as atividades de formação continuada são realizadas de modo colaborativo, uma vez que permitem o compartilhamento de momentos de reflexão, gerando diálogo em torno de interesses comuns, proporcionando a troca de informações e experiências.

Recebido em 21/04/2016, reapresentado em 30/09/2016 e aprovado em 10/10/2016

\section{Notas}

1 Compreendido por Teixeira (2011) como um ato de responsabilização do sujeito que se forma, norteado por uma dimensão reflexiva dos atos educacionais, que desencadeia a prática e os modos de se constituir no contexto da atuação docente.

\section{Referências}

BARDIN, Laurence. Análise de conteúdo. São Paulo: edições 70, 2011.

BRITO, Antonia Edna. Sobre a formação e a prática pedagógica: o saber, o saber-ser e o saber-fazer no exercício profissional. Linguagens, Educação e Sociedade, n. 12, p. 45-52, jan./jun., 2005.

IMBERNÓN, Francisco. Formação docente e profissional: formar-se para a mudança e a incerteza. São Paulo: Cortez, 2006.

Formação continuada de professores. Porto Alegre: Artmed, 2010.

LIBÂNEO, José Carlos. Reflexividade e formação de professores: outra oscilação do pensamento pedagógico?. In: PIMENTA, S. G. GHEDIN, E. (Org.). Professor reflexivo no Brasil: gênese e crítica de um conceito. São Paulo: Cortez, 2002, p. 63-93.

MENDES SOBRINHO, José Augusto de Carvalho. Formação Continuada de Professores: modelos clássicos e contemporâneos. Linguagens, Educação e Sociedade, v. 11, n. 15, p. 75-92, jul./dez., 2006. 
(Org.). Ensino de Ciência Naturais: saberes e práticas docentes. Teresina: EDUFPI, 2013.

MENEZES, Luís Carlos de. (Org.) Formação continuada de professores de ciências no contexto iberoamericano. Campinas, São Paulo: Autores Associados: NUPES, 1996.

MOREIRA, Carlos Eduardo. Formação continuada de professores: entre o improviso e a profissionalização. Florianópolis: Insular, 2002.

NÓVOA, Antonio. (Coord.). Os professores e sua formação. Lisboa: Dom Quixote, 1995.

PROCÓPIO, Marcos Vinícios Ribeiro. et al. Formação de professores em ciências: um diálogo acerca das altas habilidades e superdotação em rede colaborativa. Revista Electrónica de Ensenanza de las Ciencias, v. 9, n. 2, p. 435-456, 2011.

SELLES, Sandra Escovedo. Formação continuada e desenvolvimento profissional de professores de ciências: anotações de um projeto. Ensaio, Belo Horizonte, v. 2, n. 2, p. 01-15, 2002.

SOARES, Antonina Mendes Feitosa; MENDES SOBRINHO, José Augusto de Carvalho. A formação do professor de Ciências Naturais: rediscutindo a prática reflexiva. In: MENDES SOBRINHO, J. A. de C. (Org.). Ensino de Ciência Naturais: saberes e práticas docentes. Teresina: EDUFPI, 2013, p. 99-114.

TARDIF, Maurice. et al. O trabalho docente. São Paulo: Vozes, 2005.

TEIXEIRA, Francisca dos Santos. Narrativas de auto formação docente: desvelando modos de ser e de fazer-se professor. 2011. 147f. Dissertação (Mestrado em Educação) - UFPI/Programa de PósGraduação em Educação, Teresina, 2011.

TRIVIÑOS, Augusto Nibaldo Silva. Introdução à pesquisa em Ciências Sociais: a pesquisa qualitativa em educação. São Paulo: Atlas, 1992.

URZETTA, Fabiana Cardoso; CUNHA, Ana Maria de Oliveira. Análise de uma proposta colaborativa de formação continuada de professores de Ciências na perspectiva do desenvolvimento profissional docente. Ciência e Educação, Bauru, v. 19, n. 4, p. 841-858, 2013. 